\section{PREOCUPAÇÕES DE PROFESSORES DE EDUCAÇÃO FíSICA: REFLEXÕES ACERCA DE ESTUDOS RELACIONADOS À TEMÁTICA}

\author{
CONCERNS OF PHYSICAL EDUCATION TEACHERS: REFLECTIONS ON \\ STUDIES RELATED TO THE THEME
}

\begin{abstract}
PREOCUPACIONES DE PROFESORES DE EDUCACIÓN FISICA: REFLEXIONES ACERCA DE ESTUDIOS RELACIONADOS CON EL TEMA
\end{abstract}

\author{
Renato Daniel Trusz ${ }^{*}$, Gelcemar Oliveira Farias ${ }^{\star *}$, Alexandra Folle**, \\ Jorge Both ${ }^{* *}$
}

Palavras chave:

Docentes.

Educação Física

e treinamento.

Preocupações.

Escolas.

Keywords:

Teachers.

Physical education and training.

Concerns.

Schools.

Palabras clave: Docentes.

Educación Física y entrenamiento. Preocupaciones. Escuelas.

\begin{abstract}
Resumo: Este ensaio apresenta reflexões acerca das preocupações de professores. A partir da apresentação da Teoria de Fuller e colaboradores, que fundamenta os estudos empíricos realizados com estudantes-estagiários e professores na realidade nacional e internacional, objetivou-se refletir sobre 0 enriquecimento e o aprofundamento das pesquisas relacionadas à temática. A literatura consultada revela tanto a necessidade de observação das mudanças sofridas pela sociedade desde que a Teoria das preocupações de professores foi elaborada e redimensionada quanto a necessidade de se observar questões relacionadas ao gênero, ao contexto de atuação e aos métodos, para assim se aferirem as preocupações com maior exatidão.
\end{abstract}

\begin{abstract}
This article presents reflections on teachers' concerns. After presenting the theory of Fuller and colleagues that underlies empirical studies carried out with studentteachers and teachers in Brazil and abroad, it reflects on enrichment and deepening of research related to the theme. The literature searched reveals both the need to observe changes in society since the Theory of teachers' concerns was put forward and adjusted, and the need to observe issues related to the theme, the context of action, and methods in order to assess teachers' concerns with higher accuracy.
\end{abstract}

Resumen: Este ensayo presenta reflexiones acerca de las preocupaciones de profesores. A partir de la presentación de la Teoría de Fuller y colaboradores que fundamenta los estudios empíricos realizados con estudiantes en práctica y profesores en la realidad nacional e internacional, se pretende reflexionar sobre el enriquecimiento y profundización de las investigaciones relacionadas con ese tema. La literatura consultada revela tanto la necesidad de observar los cambios sufridos por la sociedad desde que la Teoría de las preocupaciones de profesores fue elaborada y redimensionada en cuanto a la necesidad de observar cuestiones relacionados al género, al contexto de actuación y a los métodos, para, de este modo, medir las preocupaciones con mayor exactitud.
*Prefeitura Municipal de Balneário Camboriú. Balneário Camboriú, SC Brasil.

E-mail: renato.pedagogicobc@yahoo. com.br

**Universidade do Estado de Santa Catarina. Florianópolis, SC, Brasil. E-mail: fariasgel@ hotmail.com, afolle_12@hotmail.com

${ }^{* * * U n i v e r s i d a d e ~ E s t a d u a l ~ d e ~ L o n d r i n a . ~}$ Londrina, PR, Brasil.

E-mail: jorgeboth@yahoo.com.b

Recebido em: 23-05-2016 Aprovado em: 19-09-2017

DOI: http://dx.doi.org/10.22456/1982-8918.64971 (c) (1) (8) Licence 


\section{INTRODUÇÃO}

Nas últimas décadas, tem-se percebido muitos avanços em relação às políticas públicas voltadas para a educação no Brasil. A criação da Lei de Diretrizes e Bases da Educação Nacional (1996), em sua 12ª edição (BRASIL, 2016), a proposição de Diretrizes Curriculares Nacionais para a Educação Básica (BRASIL, 2013), para a formação inicial no nível superior e para a formação continuada de professores (BRASIL, 2015), bem como a elaboração dos Planos de Educação em nível nacional, estadual e municipal, buscam melhorar a qualidade da educação nacional. Nesse contexto, a formação de professores configura-se como uma das estratégias para atingir as melhorias necessárias à educação brasileira.

No Plano Nacional da Educação (BRASIL, 2014), foram estabelecidas, dentre outras metas das políticas nacionais para a educação, a melhora da qualidade da educação superior e a garantia de formação continuada aos profissionais da educação básica, respectivamente, a formação inicial e continuada de professores. Tais metas representam um desafio tanto para as instituições formadoras quanto para as redes de ensino, uma vez que devem levar em consideração as necessidades, as demandas e as contextualizações das distintas redes de ensino.

Nessa perspectiva, vislumbrando-se a complexidade existente em cada ambiente escolar, decorrente da diversidade coma qual ele se constitui, identificar as demandas específicas dos docentes exige a compreensão de diversos fatores, que podem estar relacionados ao professor, ao contexto de trabalho e à atividade docente. Além do desenvolvimento profissional (formação, experiência, competências, valores), das condições físicas e materiais da unidade escolar (espaço físico, número de alunos, quantidade e qualidade de materiais), do ambiente onde a escola está inserida (periferia, litoral, zona rural etc.) e da comunidade escolar (classe docente, gestores, alunos e famílias), existem diferentes fatores que interferem na dinâmica de cada unidade de ensino e, consequentemente, na prática pedagógica do professor.

Os estudos relacionados ao desenvolvimento profissional docente (FEIMAN-NEMSER, 1982; BURKE et al., 1987; BARONE et al., 1996; NASCIMENTO; GRAÇA, 1998; HUBERMAN, 2000; GONÇALVES, 2000; STEFY et al., 2000; FARIAS, 2010) têm classificado a carreira docente em estágios, fases ou ciclos. Através deles, tem-se buscado esclarecer aspectos e características próprias de cada momento do percurso profissional, a partir do momento em que os professores ingressam na carreira ou desde o momento em que os estudantesestagiários são confrontados com a função docente durante sua formação inicial. Dentre tais características, podem-se citar os motivos de escolha da profissão docente, as competências profissionais, os momentos marcantes, as preocupações relacionadas à profissão, entre outros fatores a serem investigados.

A partir da referida problemática e das possibilidades de compreensão do desenvolvimento profissional expostos anteriormente, o estudo das preocupações de professores pode constituir-se numa das formas de avaliar a formação inicial e a formação continuada. Os sentimentos expressos por professores em relação a diferentes aspectos da prática pedagógica podem fornecer subsídios para a identificação de necessidades específicas durante os estágios da formação inicial que podem vir a se tornar lacunas após a formação, sendo reveladas quando da inserção dos professores nas instituições educacionais. Dessa forma, a identificação favorece as instituições formadoras na elaboração de estratégias para proporcionar uma preparação condizente com as demandas que os estagiários e os professores realmente experienciam durante seu desenvolvimento profissional. 
Com o intuito de contribuir para a ampliação e o aprofundamento de estudos relacionados à temática das preocupações de professores, em meio às propositivas investigativas do desenvolvimento profissional docente, este ensaio tem por objetivo propor reflexões acerca da Teoria das Preocupações de Fuller para apontar novos caminhos e possibilidades de investigação quanto à realidade da Educação Física no contexto brasileiro. Para isso, este ensaio foi organizado em três partes: a primeira destaca, de modo geral, a Teoria das Preocupações proposta por Fuller; a segunda apresenta os resultados de estudos encontrados em distintas áreas, tanto nacional quanto internacionalmente; enquanto a terceira ressalta reflexões acerca da dimensão impacto como a predominante na maioria dos estudos, envolvendo professores e estagiários de Educação Física na realidade brasileira.

\section{PREOCUPAÇÕES DE PROFESSORES: A TEORIA PROPOSTA POR FULLER}

Antes de abordar alguns pressupostos referentes à teoria em questão, é necessário delimitar o termo preocupação associado à profissão docente. Dessa forma, destaca-se que uma preocupação, no ambiente educacional, acarreta sentimentos e inquietações diante de situações cujo desfecho é imprevisível (RIOPEL, 2006). Nesse sentido, a associação do termo à profissão docente se faz necessária para melhor compreender o desenvolvimento profissional, uma vez que um indivíduo pode apresentar uma infinidade de preocupações relacionadas à sua vida pessoal que não estão vinculadas à realidade e ao cotidiano da profissão.

O estudo acerca dessa temática com a população docente teve início com as pesquisas de Fuller (1969), Fuller e Parsons (1972), Fuller, Parsons e Watkins (1974) e Fuller e Bown (1975) nos Estados Unidos. A partir dos depoimentos de estudantes (futuros professores), que relatavam não se sentirem devidamente preparados para exercer a profissão depois de formados, constatou-se que a formação inicial não atendia o processo de socialização de uma forma adequada. Nesse sentido, Fuller (1969) buscou compreender como se sentiam os alunos estagiários em distintos momentos de suas formações.

A partir do desenvolvimento da teoria (FULLER, 1969), foram identificadas e categorizadas as preocupações de professores em três momentos da formação, quais eram: a fase anterior às experiências de ser professor (Pre-Teaching), a fase de início das atividades no papel de professor (Early Teaching) e a fase após o período de experiência, quando o professor/aluno já adquire certo nível de experiência com a função (Late Teaching). Nesse sentido, o que poderia se esperar dos professores formadores, a partir da teoria, era a proposição e o desenvolvimento de estratégias, nas quais os futuros professores pudessem adquirir experiências mais próximas possíveis da realidade da função de professor.

Atualmente, percebe-se, em relação aos currículos dos cursos de formação de professores, uma evolução quanto aos componentes curriculares que possibilitam essa inserção na realidade escolar. Inicialmente, com os estágios curriculares ao final do curso e, mais recentemente, devendo a Prática como Componente Curricular ocorrer desde 0 início do curso, não ficando restrito o contato com a realidade escolar apenas para o estágio supervisionado (BRASIL, 2002, 2015). Todavia, ainda se faz necessária a realização de estudos que forneçam indícios ou possibilidades de realização de práticas pedagógicas que tenham impacto significativo durante a formação inicial (MARCON; GRAÇA; NASCIMENTO, 2011). 
Desde o primeiro estudo (FULLER, 1969), quando foi conceituada a teoria, categorizando as preocupações em consigo próprio (self) e com pupilos (pupils), até a reconceituação da teoria (FULLER; PARSONS; WATKINS, 1974), que apresenta as dimensões consigo próprio (self), com a tarefa (task) e com o impacto (impact), destaca-se o seu caráter evolutivo, decorrente da aquisição de experiência pelos professores. Neste cenário, as preocupações consigo próprio são predominantes durante os primeiros contatos com a função de ser professor, ou seja, geralmente durante os estágios realizados na formação inicial, bem como durante 0 início da carreira. Compreendem, assim, as inquietações relacionadas à "sobrevivência" como professor, como controlar a disciplina dos alunos e também o fazer pedagógico, o receio de ser observado e fracassar perante supervisores, equipe pedagógica e comunidade escolar, além da necessidade de obter uma avaliação favorável do seu ensino (FULLER; PARSONS; WATKINS, 1974).

As preocupações com a tarefa de ensinar tendem a se manifestar após um curto período de experiência com a função docente, quando o professor passa a preocupar-se com as situações de ensino, como o número elevado de alunos por turma, o excesso de tarefas, a falta de materiais, a ausência de espaço físico adequado para ministrar a aula, o pouco tempo para realizar planejamento ou ainda o fato de sentir-se pressionado para realizar essas tarefas (MATOS et al., 1991; COSTA, 2013).

Por fim, após adquirir certas competências resultantes das experiências vividas na função docente, a tendência é que a predominância das preocupações passe a ser na dimensão impacto. Essas se relacionam a aspectos referentes aos alunos, como o reconhecimento das suas necessidades sociais e emocionais, a busca por atender a todos os alunos em seu planejamento, dentre outros fatores (FULLER; PARSONS; WATKINS, 1974).

Salienta-se que, para o desenvolvimento da teoria, os dados referentes às preocupações dos estagiários foram coletados por meio de procedimentos qualitativos, como entrevistas não estruturadas e um formulário nomeado Concerns Statement Form. O formulário caracterizavase como um instrumento composto por questões abertas que buscavam identificar se 0 estudante tinha experiência com ensino, de que tipo e quanto tempo de experiência, quais as preocupações com o ensino que o estavam afligindo naquele momento e, por fim, quais as vantagens e as satisfações que percebia como relacionadas ao ensino. A partir destes, foram desenvolvidos métodos mais formais para a aferição das preocupações, como 0 Teacher Concerns Statement (TCS), que continha uma questão aberta que objetivava aferir se as preocupações dos professores estavam relacionadas à dimensão consigo próprio ou à dimensão pupilos através de escores associados a seis categorias de preocupações, sendo três relacionadas à primeira dimensão (função, adequação e ser aceito pelos alunos) e três relacionadas à segunda (ensino, necessidades dos alunos e melhorias educacionais); o Teacher Concerns Checklist (TCCL-B), que foi estruturado em função das limitações encontradas no TCS e que continha 56 assertivas, relacionadas às dimensões consigo próprio, situacional e impacto, em que o professor deveria assinalar o quanto estava preocupado em uma escala com cinco níveis (PARSONS; FULLER, 1974), além do Teacher Concerns Questionaire (TCQ) (GEORGE, 1978), o qual apresenta quinze assertivas que contemplam as três dimensões propostas na teoria, devendo-se marcar o nível de preocupação em uma escala que varia de 1 (not concerned) a 5 (extremely concerned). 0 questionário foi traduzido para a língua portuguesa como Questionário Acerca das Preocupações do Professor (MATOS et al., 1991) e 
adaptado para futuros professores de Educação Física como Teacher Concerns Questionaire - Physical Education (MCBRIDE, 1993), este último traduzido e validado para a realidade brasileira como Escala de Preocupações de Professores (COSTA, 2013). As assertivas presentes no questionário e as dimensões correspondentes são apresentadas no Quadro 1. Por meio da análise dos escores em cada uma das assertivas é possível identificar a ou as dimensões de preocupação predominantes em determinado professor.

Quadro 1 - Assertivas e dimensões da Escala de Preocupações de Professores.

\begin{tabular}{|c|c|}
\hline Dimensão & Assertiva \\
\hline \multirow{5}{*}{$\begin{array}{l}\text { Consigo próprio } \\
\text { (self) }\end{array}$} & Ensinar bem quando estou sendo observado \\
\hline & Ser aceito e respeitado por outros professores \\
\hline & Sentir-me mais confortável como professor \\
\hline & Obter uma avaliação favorável/positiva sobre o meu ensino \\
\hline & Manter o nível apropriado de controle da turma \\
\hline \multirow{5}{*}{$\begin{array}{l}\text { Com a tarefa de ensinar } \\
\text { (task) }\end{array}$} & Falta de continuidade no planejamento anual da disciplina de Educação Física \\
\hline & Falta de apoio administrativo para disciplina de Educação Física \\
\hline & Falta de uma política consistente de avaliação na disciplina de Educação Física \\
\hline & Trabalhar com turmas muito grandes \\
\hline & Com o reduzido número de aulas no programa de horários da escola \\
\hline \multirow{5}{*}{$\begin{array}{l}\text { Com o impacto do } \\
\text { ensino } \\
\text { (impact) }\end{array}$} & Ir ao encontro das necessidades dos diferentes tipos de alunos \\
\hline & Identificar problemas de aprendizagem dos alunos \\
\hline & Desafiar os alunos desmotivados \\
\hline & Orientar os alunos para alcançarem o crescimento intelectual e emocional \\
\hline & Se os alunos estão sendo atendidos nas suas necessidades \\
\hline
\end{tabular}

Fonte: Adaptado de Costa (2013, p 107).

A evolução da teoria e a importância atribuída para a análise das preocupações de professores de diferentes áreas do conhecimento levaram, assim, à realização de diversas investigações em diferentes países do mundo, encontrando-se um cenário investigativo interessante para reflexões no cenário educacional e de formação no âmbito superior.

\section{REFLEXÕES SOBRE A PRODUÇÃO CIENTÍFICA: O CENÁRIO DAS INVESTIGAÇÕES SOBRE AS PREOCUPAÇÕES DE PROFESSORES}

Dentre a produção consultada acerca da temática, percebe-se que ela tem recebido atenção de distintas áreas de formação de professores. Os estudos envolvendo estudantes/ professores atuantes no ensino primário e secundário em geral (JANSSENS, 1987; OLSEN; HEYSE, 1990), e específicos nas áreas de Ciências (ZIELINSKI; PRESTON, 1992; BEJARANO; CARVALHO, 2003; 2004), Artes (REEVES-KAZELSKIS; KING, 1994) e Educação Física (WENDT; BAIN, JACKSON, 1981; MCBRIDE; BOGGESS; GRIFFEY, 1986; BEHETS, 1990; MATOS et al., 1991; MEEK, 1996; CONKLE, 1996; MEEK; BEHETS, 1999; FARIAS, 2000; ZOUNHIA; HATZIHARISTOS; EMMANOUEL, 2004; LOCH et al., 2005; FARIAS et al. 2008; FOLLE; NASCIMENTO, 2011; PIOVANI; BOTH; NASCIMENTO, 2012; COSTA, 2013; SILVA PIOVANI; BOTH, 2014; RIBEIRO et al., 2015) têm revelado certa complexidade quanto à compreensão das preocupações profissionais, uma vez que tanto procedimentos de coleta 
quanto métodos de análise dos dados têm apontado divergências em seus resultados, inclusive, em contextos e populações semelhantes.

Para fins de análise e comparação dos resultados apresentados na literatura consultada, foi utilizado o ciclo de desenvolvimento profissional em que as populações das amostras se encontram ou forneceram dados. Nesse sentido, assume-se a categorização proposta por Farias e Nascimento (2012) pelo fato dos autores investigarem a carreira considerando diferentes aspectos que demarcam a sua intervenção profissional, ao mesmo tempo em que estudaram, especificamente, os professores de Educação Física, sendo classificados conforme os ciclos apresentados no Quadro 2.

Quadro 2 - Ciclos de desenvolvimento profissional de professores de Educação Física

\begin{tabular}{|c|c|}
\hline Ciclos & Características da Carreira \\
\hline $\begin{array}{l}\text { Entrada na Carreira } \\
1 \text { a } 4 \text { anos de docência }\end{array}$ & $\begin{array}{l}\text { Tomada de decisão: desejo de permanecer na docência } \\
\text { Choque com a realidade: situações vivenciadas que exigem a aquisição } \\
\text { de competências profissionais }\end{array}$ \\
\hline $\begin{array}{l}\text { Consolidação das Competências } \\
\text { Profissionais na Carreira } \\
5 \text { a } 9 \text { anos de docência }\end{array}$ & $\begin{array}{l}\text { Diversificação das fontes de conhecimento } \\
\text { Aquisição de competências profissionais } \\
\text { Alteração das estratégias metodológicas }\end{array}$ \\
\hline $\begin{array}{l}\text { Afirmação e Diversificação na } \\
\text { Carreira } \\
10 \text { a } 19 \text { anos de docência }\end{array}$ & $\begin{array}{l}\text { Domínio das rotinas básicas } \\
\text { Partilha com os pares da Educação Física e das demais áreas } \\
\text { Mudança de trajetória - cargos administrativos } \\
\text { Surgimento de expectativas profissionais } \\
\text { Aquisição de metacompetências profissionais }\end{array}$ \\
\hline $\begin{array}{l}\text { Renovação na Carreira } \\
20 \text { a } 27 \text { anos de docência }\end{array}$ & $\begin{array}{l}\text { Professores ainda encantados com a docência } \\
\text { Professores defensores da causa docente } \\
\text { Professores renovadores da atuação profissional }\end{array}$ \\
\hline $\begin{array}{l}\text { Maturidade na Carreira } \\
28 \text { a } 38 \text { anos de docência }\end{array}$ & $\begin{array}{l}\text { Conhecimento Tácito } \\
\text { Aposentadoria: sentimento de realização profissional }\end{array}$ \\
\hline
\end{tabular}

Por meio da análise de investigações, em que as amostras foram compostas por estagiários e professores nos distintos ciclos de desenvolvimento profissional (WENDT; BAIN; JACKSON, 1981; OLSEN; HEYSE, 1990; BEHETS, 1990; MATOS et al., 1991; ZIELINSKI; PRESTON, 1992; REEVES-KAZELSKIS; KING, 1994; CONKLE, 1996; MEEK, 1996; MEEK; BEHETS, 1999; FARIAS, 2000; BEJARANO; CARVALHO, 2003; ZOUNHIA; HATZIHARISTOS; EMMANOUEL, 2004; LOCH et al., 2005; FARIAS et al., 2008; PIOVANI; BOTH; NASCIMENTO, 2012; COSTA, 2013; SILVA PIOVANI; BOTH, 2014; RIBEIRO et al., 2015), ou que foram obtidos dados acerca dos ciclos vivenciados por professores durante a carreira (FOLLE; NASCIMENTO, 2011), tem-se revelado a predominância de preocupações relacionadas à dimensão impacto seguida, em alguns destes, por preocupações consigo próprio.

Resultados distintos desses puderam ser identificados no estudo de Janssens (1987), no qual as preocupações de professores iniciantes do primário tiveram predomínio na dimensão consigo próprio, seguidas daquelas com a tarefa. O estudo de Behets (1990) obteve resultados similares com estudantes estagiários de Educação Física, assim como o estudo de Bejarano e Carvalho (2004), no qual foi identificada predominância na dimensão consigo próprio em um estudante-estagiário de Física. Além desses resultados em populações no ciclo de entrada na carreira docente, também foi identificada predominância na dimensão tarefa de ensinar em professores de Educação Física no ciclo de desinvestimento (COSTA, 2013). 
Dentre as análises realizadas em alguns dos estudos (MCBRIDE; BOGGESS; GRIFFEY, 1986; ZOUNHIA; HATZIHARISTOS; EMMANOUEL, 2004; LOCH et al., 2005; FARIAS et al., 2008), tem-se observado que estudantes e professoras têm apresentado níveis de preocupação mais elevados que seus pares do sexo masculino em todas as dimensões. Por outro lado, o estudo de Ribeiro et al. (2015) não identificou diferenças significativas ao comparar participantes do sexo masculino e feminino. Dessa forma, faz-se necessária a realização de estudos mais aprofundados em relação às preocupações de professoras e futuras professoras, utilizando-se de métodos que atendam à necessidade de compreender ou identificar questões de gênero que exercem influência na formação pessoal, profissional e também no desenvolvimento profissional de mulheres e homens.

Quanto aos instrumentos utilizados para aferir as preocupações de professores e futuros professores nos estudos analisados, existe predominância na utilização de questionários. Um dos instrumentos mais utilizados é o Teacher Concerns Questionnaire (TCQ), desenvolvido por George (1978), aplicado nos Estados Unidos (MCBRIDE; BOGGESS; GRIFFEY, 1986), sendo traduzido e aplicado em Portugal (MATOS; GOMES; GRAÇA; QUEIRÓZ, 1991), no Brasil (FARIAS, 2000; LOCH et al., 2005; FARIAS et al. 2008; RIBEIRO et al., 2015), no Uruguai (PIOVANI; BOTH; NASCIMENTO, 2012; SILVA PIOVANI; BOTH, 2014), na Grécia (ZOUNHIA; HATZIHARISTOS; EMMANOUEL, 2004), na Grã-Bretanha (MEEK, 1996) e na Bélgica (BEHETS, 1990). Entretanto, ele tem sido apontado como insuficiente ou inadequado para aferir as preocupações de professores em diferentes culturas, áreas de conhecimento e populações (MCBRIDE; BOGGESS; GRIFFEY, 1986; MEEK, 1996; REEVES-KAZELSKIS; KING, 1994).

Nesse sentido, alguns dos estudos que buscaram validar o instrumento e identificaram as lacunas relatadas acima possibilitaram a realização de outros estudos, bem como a adaptação do questionário para realidades específicas, como é o caso da adaptação do questionário para estudantes-estagiários na área de Ciências (ZIELINSKI; PRESTON, 1992), a adequação do questionário para a área de Educação Física nos Estados Unidos por McBride (1993), na Inglaterra (CONKLE, 1996) e no Brasil (COSTA, 2013).

Não só a adequação de metodologias quantitativas, mas também a utilização de métodos qualitativos, como o diário de campo (JANSSENS, 1987; BEHETS, 1990), entrevistas (JANSSENS, 1987; OLSEN; HEYSE, 1990; FOLLE; NASCIMENTO, 2011), questionários com questões abertas (PIOVANI; BOTH; NASCIMENTO, 2012) e também a utilização de mais de um instrumento, como entrevista, diário de campo e filmagens (BEJARANO; CARVALHO, 2003; 2004) também foram utilizados com o intuito de obter dados mais aprofundados em relação às preocupações de futuros professores e professores em serviço.

Comparando-se os resultados obtidos em estudos que se utilizaram de metodologias e de instrumentos quantitativos com outros em que foram utilizados métodos qualitativos para identificar a dimensão predominante das preocupações de professores, pode-se inquirir que o resultado é influenciado pela metodologia adotada, visto que os dados identificados são controversos. $O$ estudo em que essa situação fica mais em evidência é o realizado por Behets (1990), em que se utilizou o TCQ em conjunto com um diário de campo, sendo verificada a predominância de preocupações em dimensões diferentes. Assim, o autor sugere a existência de preocupações reais (expressas de forma subjetiva e analisadas qualitativamente) e preocupações ideais (expressas de forma objetiva e analisadas quantitativamente). 0 que 0 
autor identifica e que se questiona, nesse ensaio, é a possibilidade de estudantes-estagiários sentirem-se avaliados por seus supervisores constantemente e terem conhecimento acerca do que é esperado deles durante a realização dos estágios. Nesse sentido, a utilização do instrumento com assertivas nas quais se deve colocar o quanto se está preocupado pode induzir os respondentes a marcar níveis mais elevados em assertivas relacionadas à dimensão impacto.

Da mesma forma, estudos em que são utilizados questionários com questões fechadas e metodologias quantitativas têm possibilitado o questionamento quanto à predominância de preocupações com o impacto; os estudos em que se utilizam metodologias qualitativas e questionários com questões abertas e diário de campo podem acarretar julgamentos de que os resultados serão sempre opostos. Entretanto, os estudos de Bejarano e Carvalho (2003; 2004), utilizando-se dos mesmos instrumentos de coleta, identificaram predomínio em dimensões distintas nos dois sujeitos investigados. Enquanto um dos sujeitos apresentava predomínio na dimensão consigo próprio, o outro apresentou predomínio na dimensão impacto, o que permite sugerir que aspectos relacionados ao desenvolvimento profissional e também questões contextuais específicas da prática docente podem exercer influência nas preocupações dos professores (PIOVANI; BOTH; NASCIMENTO, 2012).

Para tanto, as investigações realizadas em diferentes nacionalidades, com estudantes e professores de diferentes áreas do conhecimento, em especial em Educação Física, e com diversificadas metodologias de pesquisa, têm revelado a inquietação acentuada com a dimensão impacto das preocupações de professores propostas por Fuller, Parsons e Watkins (1974). Fato que desvenda um novo cenário para o estudo das preocupações de professores, ao mesmo tempo em que se tecem novas dimensões para a compreensão desta temática.

\section{PREOCUPAÇÕES COM O IMPACTO: A DIMENSÃO DESTACADA POR PROFESSORES E ESTUDANTES DE EDUCAÇÃO FÍSICA NA REALIDADE BRASILEIRA}

Um dos aspectos que pode ser destacado acerca dos estudos realizados na realidade brasileira diz respeito à predominância de preocupações com a dimensão impacto presente em estudantes e professores de Educação Física que se encontram no ciclo de entrada na carreira (FARIAS, 2000; LOCH et al., 2005; FARIAS, et al., 2008; COSTA, 2013; RIBEIRO et al., 2015). Acerca destes resultados, podem-se realizar duas reflexões que caminham em direções opostas.

A primeira diz respeito à ressignificação da teoria no contexto brasileiro. Cabe aqui fazer referência ao contexto sócio-histórico em que os estudos de Fuller e colaboradores foram conduzidos. É necessário compreender que as preocupações com o impacto apresentadas quando da elaboração da teoria relacionavam-se predominantemente com as situações de aprendizagem. Conforme explicitado por Fuller, Parsons e Watkins (1974), a dimensão impacto tem a ver, principalmente, com o reconhecimento de necessidades individuais dos alunos e adaptação do professor quanto a métodos de ensino e estratégias, na tentativa de se atender a essas necessidades. Assim, mudanças de ordem política, econômica e social que vêm ocorrendo desde a década de 1970, não só nos Estados Unidos, mas também no Brasil e no restante do mundo, impreterivelmente, exercem influência sobre aspectos relacionados à escola e ao ensino. 0 advento de legislações educacionais, metodologias de ensino, 
reformas curriculares de base e de formação de professores, assim como os problemas sociais enfrentados por grande parcela da população brasileira, acarreta preocupações não só ao impacto do ensino, mas também ao impacto da educação na vida dos educandos.

Tais afirmativas sugerem a necessidade de identificar se a teoria pode ser ampliada, a partir da emergência de outras dimensões de preocupações nos professores e futuros professores (REEVES-KAZELSKIS; KING, 1994). Nesse sentido, uma ampliação e/ou ressignificação da teoria poderia ser identificada como em estudo realizado no Canadá, no qual Riopel (2006) analisou as preocupações de 240 professores de ensino médio e fundamental nas cidades de Montreal, Vancouver e Toronto. A partir da análise, identificaram-se três grupos de preocupações, as quais são específicas do professor, do distrito de trabalho e, por último, daquelas gerais e percebidas nos professores de todos os distritos. Dentre as preocupações gerais dos professores atuantes em escolas, o autor categoriza em quatro grupos, quais sejam: "1) problemas sociais que afetam os alunos; 2) êxito escolar de todos os alunos; 3) certas condições de trabalho dos professores e 4) permanência da sua filosofia da educação num contexto de mobilidade social e política" (RIOPEL, 2006, p. 166). Mesmo sendo um estudo em que não é abordada a Teoria de Fuller (1969), destaca-se que as categorias identificadas apresentam-se muito mais consistentes com o cenário sociopolítico atual, o que pode auxiliar na proposição de dimensões de preocupações na realidade brasileira, uma vez que, assim como o Brasil, o Canadá também se apresenta como uma nação de proporções continentais e que possui professores exercendo sua profissão em contextos e condições distintas.

A partir disso, surgem duas possibilidades de compreensão dos resultados. A primeira possibilidade decorre de os professores brasileiros do ciclo de entrada já apresentarem desde cedo preocupações predominantes com aspectos da dimensão impacto, em virtude de vivenciarem as condições de pobreza e de marginalização a que os alunos estão submetidos, o que pode representar uma inversão na evolução das preocupações e também a extinção das preocupações consigo próprio. A segunda possibilidade provém de que as estratégias propostas nas reformas curriculares para a formação de professores estejam, de fato, atingindo seus objetivos e, assim, formando adequadamente os futuros professores. Com isso, faz-se necessário que as investigações acerca das preocupações dos estudantes ocorram mais precocemente durante a formação inicial, para que se possa aferir se, realmente, o processo evolutivo das preocupações de professores ocorre conforme proposto na teoria. Nesse sentido, as preocupações consigo próprio e com a tarefa poderiam ser manifestadas durante o primeiro ou o segundo ano de formação.

Na direção oposta, a segunda reflexão alerta para a possibilidade de as metodologias utilizadas para acessar as preocupações dos professores não estarem sendo suficientes ou adequadas para este fim, indo ao encontro de outros estudos realizados internacionalmente (MCBRIDE; BOGGESS; GRIFFEY, 1986; BEHETS, 1990; MEEK, 1996; REEVES-KAZELSKIS; KING, 1996). Nos estudos consultados, em que a dimensão impacto tem sido predominante, independentemente do ciclo de desenvolvimento profissional em que os professores se encontram (FARIAS, 2000; LOCH et al., 2005; FARIAS et al., 2008; COSTA, 2013; RIBEIRO et al., 2015), pode-se perceber a utilização dos questionários TCQ e TCQ-PE, nos quais são feitas análises quantitativas dos dados. O que se sugere, neste ensaio, é a utilização de mais de uma técnica de aferição com análise qualitativa das informações, como utilizado por Behets (1990), Bejarano e Carvalho (2003; 2004) e Folle e Nascimento (2011), uma vez que a abordagem 
qualitativa permite ao pesquisador identificar sentidos e significados que muitas vezes não são perceptíveis através de análises quantitativas.

Finalizando, percebe-se, a partir da literatura consultada, a escassez de estudos envolvendo professores provenientes de distintos estágios da carreira docente ou de acompanhamento destes professores em estudos longitudinais. Esse fato pode ocorrer em decorrência da facilidade em se obter amostras dentro do contexto das universidades, enquanto as investigações nas redes de ensino envolvem questões administrativas e legais que por vezes acarretam dificuldades para se ter acesso à população de professores. Na realidade da Educação Física no Brasil, os estudos envolvendo professores durante a carreira (FARIAS, 2000; FOLLE; NASCIMENTO, 2011; COSTA, 2013) e alunos em situação de estágio (LOCH et al., 2005; FARIAS et al., 2008; RIBEIRO et al., 2015) apresentam-se bem distribuídos. Entretanto, a produção relacionada à temática ainda é incipiente, configurando-se como um campo fértil para a realização de novas investigações. Nota-se, ainda, que a produção se concentra em sua maioria na Região Sul do Brasil, à exceção do estudo de Costa (2013), que foi realizado no Rio de Janeiro.

Independentemente dos fatores que determinam a dimensão com o impacto, permitese afirmar que, na realidade brasileira, existe uma acentuada preocupação dos professores e futuros professores com o seu alunado, o que remete a destacar as questões sociais presentes no ambiente escolar. Todavia, seria necessária, como dito anteriormente, a realização de estudos aprofundados sobre a teoria das preocupações no intuito de redimensionar na atualidade o que realmente preocupa o docente.

\section{CONCLUSÕES}

A partir da análise dos estudos realizados referentes à temática das preocupações de professores, destaca-se a necessidade de ampliação de investigações na realidade brasileira. Concebendo a temática como uma das formas de analisar e avaliar a formação inicial e continuada de professores, é de suma importância que as instituições formadoras e redes de ensino busquem compreender as necessidades de seus alunos/professores para assim implementar estratégias que realmente se apresentem como válidas para o desenvolvimento profissional destes.

Para que sejam atendidos essesfins, lacunas referentes à teoria precisamser elucidadas, ao que este ensaio se propôs a apontar alguns caminhos para tal. Questões relacionadas ao gênero e aos métodos de coleta foram algumas das indagações apresentadas, entretanto, o contexto sociopolítico-econômico, por toda sua complexidade, permite realizar outras que possivelmente não foram vislumbradas neste espaço e momento. Não só de modo geral, mas também especificamente, as preocupações de professores devem ser compreendidas de forma muito mais ampla em decorrência do contexto em que cada professor está inserido.

Nesta perspectiva, as informações apresentadas a partir da literatura consultada, desde a apresentação do marco teórico até as implicações empíricas, permitem a sugestão de investigações mais profundas em todo o território nacional, com destaque para a área da Educação Física e de acompanhamento de professores em estudos longitudinais que visem à identificação das mudanças ou reforços nas preocupações ao longo dos diferentes estágios de desenvolvimento profissional desta classe. 


\section{REFERÊNCIAS}

BARONE, Thomas et al. A future for teacher education: developing a strong sense of professionalism. In: SIKULA, John et al. (Org.). Handbook of research on teacher education. $2^{\text {nd }}$ ed. New York: Macmillan, 1996. p. 1108-1149.

BEHETS, Daniël. Concerns of preservice Physical Education teachers. Journal of Teaching in Physical Education, v. 10, n. 1, p. 66-75, 1990.

BEJARANO, Nelson R.; CARVALHO, Anna M. Tornando-se professor de ciências: crenças e conflitos. Ciência e Educação, v. 9, n. 1, p. 1-15, 2003.

BEJARANO Nelson R.; CARVALHO, Anna M. A História de Ely: um professor de Física no início da carreira. Revista Brasileira de Ensino de Física, v. 26, n. 2, p. 165-178, 2004.

BRASIL. Câmara dos Deputados. Lei de Diretrizes e Bases da Educação Nacional. 11. ed. Brasília: Edições Câmara, 2015a.

BRASIL. Ministério da Educação. Resolução № 2, de 1ำ de julho de 2015. Define as Diretrizes Curriculares Nacionais para a formação inicial em nível superior (cursos de licenciatura, cursos de formação pedagógica para graduados e cursos de segunda licenciatura) e para a formação continuada. Brasília: Associação Brasileira de Mantenedoras de Ensino Superior, 2015b.

BRASIL. Lei Federal no 13005/2014, de 25 de junho de 2014. Aprova o Plano Nacional de Educação PNE e dá outras providências. Diário Oficial da União, Brasília, DF, 26 jun.2014. Edição extra.

BRASIL. Ministério da Educação. Conselho Nacional de Educação. RESOLUÇÃO CNE/CP № 1, de 18 de fevereiro de 2002. Brasília, 2002. Disponível em: <http://portal.mec.gov.br/seesp/arquivos/pdf/ res1 2.pdf>. Acesso em: 31 out. 2016.

BRASIL. Ministério da Educação. Secretaria de Educação Básica. Secretaria de Educação Continuada, Alfabetização, Diversidade e Inclusão. Secretaria de Educação Profissional e Tecnológica. Conselho Nacional da Educação. Câmara Nacional de Educação Básica. Diretrizes Curriculares Nacionais Gerais da Educação Básica. Brasília, 2013.

BURKE, Peter et al. The teacher career cycle: model development and research report. In: ANNUAL MEETING OF THE AMERICAN EDUCATIONAL RESEARCH ASSOCIATION, 71., 1987. Washington. Annals... Washington: AERA, 1987. p. 1-59.

COSTA, Bruno. Preocupações pedagógicas e desenvolvimento profissional em Educação Física: passo ou descompasso? 2013. 120f. Dissertação (Mestrado) - Instituto de Educação e Instituto Multidisciplinar, UFRRJ, Seropédica, 2013.

FARIAS, Gelcemar 0.0 percurso profissional dos professores de Educação Física: rumo à prática pedagógica, 2000. 117 f. Dissertação (Mestrado) - Centro de Desportos, UFSC, Florianópolis, 2000.

FARIAS, Gelcemar O. Carreira docente em Educação Física: uma abordagem na construção da trajetória profissional do professor, 2010. 303 f. Tese (Doutorado) - Centro de Desportos, UFSC, Florianópolis, 2010.

FARIAS, Gelcemar O.; NASCIMENTO, Juarez V. Construção da identidade profissional: metamorfoses na carreira docente em educação física. In: FARIAS, Gelcemar O.; NASCIMENTO, Juarez V. Construção da identidade profissional em Educação Física: da formação à intervenção. Florianópolis: Ed. da UDESC, 2012. p. 61-80. 
FARIAS, Gelcemar O. et al. Preocupações pedagógicas de estudantes-estagiários na formação inicial em Educação Física. Motriz, v.14, n.3, p.310-319, jul./set. 2008.

FEIMAN-NEMSER, Sharon. Staff development and learning to teach. In: ANNUAL MEETING OF THE EASTERN EDUCATIONAL RESEARCH ASSOCIATION, 1., 1982. Detroit. Annals... Detroit: AERA, 1982. p. 1-18.

FOLLE, Alexandra; NASCIMENTO, Juarez V. Preocupações ao longo da carreira docente: estudos de caso com professores de Educação Física do magistério público estadual. Revista Brasileira de Ciências do Esporte, v. 33, n. 4, p. 841-856, out./dez. 2011.

FULLER, Frances. Concerns of teachers: a developmental conceptualization. American Education Research Journal, v. 6, n. 2, p. 207-226, Mar. 1969.

FULLER, Frances; PARSONS, Jane. Current Research on the Concerns of teachers. In: ANNUAL MEETING OF THE AMERICAN EDUCATION RESEARCH ASSOCIATION, 56., 1972. Chicago. Annals... Chicago: AERA, 1972. p. 1-18.

FULLER, Frances; PARSONS, Jane; WATKINS, James. Concerns of teachers: research and reconceptualization. In: ANNUAL MEETING OF THE AMERICAN EDUCATION RESEARCH ASSOCIATION, 58., 1974. Chicago. Annals... Chicago: AERA, 1974. p. 1-68.

FULLER, Frances; BOWN, Oliver. Becoming a teacher. In: RYAN, K. (Ed.). Teacher education: (74th yearbook of the National Society for the Study of Education). Chicago: University of Chicago, 1995. Pt. 2, p. 25-52.

GEORGE, Archie. Measuring self, task, and impact concerns: a manual for the teacher concerns questionnaire. Austin: The University of Texas, R\&D Center for Teacher Education, 1978.

GONÇALVES, José. A carreira das professoras do ensino primário. In: NÓVOA, Antônio. Vidas de professores. 2. ed. Porto: Porto Editora, 2000. p. 141-169.

GONÇALVES, José. Desenvolvimento profissional e carreira docente: fases da carreira, currículo e supervisão. Sísifo, n. 8, p. 23-36, jan./abr. 2009.

HUBERMAN, Michaël. O ciclo de vida profissional dos professores. In: NÓVOA, Antônio Vidas de professores. 2. ed. Porto: Porto Editora. 2000. p. 31-61.

JANSSENS, Steven. A description of concerns of beginning teachers: the results of a qualitative study with some methodological considerations. In: ANNUAL MEETING OF THE AMERICAN EDUCATION RESEARCH ASSOCIATION, 71., 1987. Washington. Annals... Washington: AERA, 1987. p. 1-22.

LOCH, Mathias et al. Preocupações pedagógicas e profissionais de formandos em Educação Física do Sul do Brasil. EFEDEPORTES, Buenos Aires, v. 10, n. 80, Ene., 2005. Disponível em: <http://www. efdeportes.com/revista digital>. Acesso em: 31 out. 2016.

MARCON, Daniel; GRAÇA, Amândio; NASCIMENTO, Juarez V. Critérios para a implementação de práticas pedagógicas na formação inicial em Educação Física e implicações no conhecimento pedagógico do conteúdo dos futuros professores. Revista Brasileira de Educação Física e Esporte, v. 25, n. 3, p. 497-511, jul./set. 2011.

MATOS, Zélia et al. A valorização dos problemas em situação de estágio: preocupações dos estudantes-estagiários e formadores. In: BENTO, Jorge; MARQUES, António. As ciências do desporto na escola. Porto: FCDEF, 1991. p. 359-367. 
MCBRIDE, Ronald. The TCQ -- PE: An adaptation of the Teacher Concerns Questionnaire Instrument to a physical education setting. Journal of Teaching in Physical Education, v. 12, n. 2, p. 188-196, Jan. 1993.

McBRIDE, Ronald; BOGGESS, Theresa; GRIFFEY, David. Concerns of in service physical education teachers as compared with Fuller's concern model. Journal of Teaching in Physical Education, v. 5, n. 3, p. 149-156, Apr. 1986.

MEEK, Geoffrey. The teacher concerns questionnaire with preservice physical educators in Great Britain: being concerned with concerns. Journal of Teaching in Physical Education, v. 16, n. 1, p. 20-29, Oct. 1996.

MEEK, Geoffrey; BEHETS, Daniël. Physical education teachers' concerns towards teaching. Teaching and Teacher Education, v. 15, n. 5, p. 497-505, Jul. 1999.

NASCIMENTO, Juarez V.; GRAÇA, Amândio. A evolução da percepção de competência profissional de professores de Educação Física ao longo da carreira docente. In: CONGRESSO DE EDUCAÇÃO FÍSICA E CIÊNCIAS DO DESPORTO DOS PAÍSES DE LÍNGUA PORTUGUESA, 6., 1998, La Coruña. Actas... La Coruña: INEF Galícia, 1998. p. 320-335.

OLSEN, Dwaine; HEYSE, Kathy. Development and concerns of first-year and reentry teachers with and without mentors. In: ANNUAL MEETING OF THE AMERICAN EDUCATION RESEARCH ASSOCIATION, 74., 1990, Boston. Annals... Boston: AERA, 1990. p. 1-24.

PARSONS, Jane; FULLER, Frances. Concerns of teachers: Recent research on two assessment instruments. In: ANNUAL MEETING OF THE AMERICAN EDUCATION RESEARCH ASSOCIATION, 58. 1974. Chicago. Annals... Chicago: AERA, 1974. p. 1-14.

PIOVANI, Verónica Silva; BOTH, Jorge. Relaciones entre el tiempo de realización de práctica docente curricular y las preocupaciones pedagógicas de estudiantes de educación física de Uruguay. Educación Física y Deporte, v. 33, n. 2, p. 443-466, Jul./Dic. 2014.

PIOVANI, Verónica S.; BOTH, Jorge; NASCIMENTO, Juarez V. Preocupaciones pedagógicas de los Estudiantes practicantes de Educación Física de diferentes domicilios sociales de Uruguay. Movimento, v. 18, n. 4, p. 77-98, out./dez. 2012.

REEVES-KAZELSKIS, Carolyn; KING, Debra. Teaching concerns of preservice teachers. In: ANNUAL MEETING OF THE MID-SOUTH EDUCATION RESEARCH ASSOCIATION, 23 ${ }^{\text {rd }}$., 1994. Nashville. Annals... Nashville: MSERA, 1994. p. 1-21.

RIBEIRO, Vandressa et al. Preocupações pedagógicas e competência profissional de estudantes de Educação Física em situação de estágio. Revista da Educação Física/UEM, v. 26, n. 1, p. 59-68, 1. trim. 2015.

RIOPEL, Marie-Claude. Novas regulações escolares: quais os impactos sobre as preocupações dos professores? Educação em Revista, v. 44, p. 165-184, dez. 2006.

STEFY, Betty et al. The model and its application. In: STEFY, Betty et al. Life cycle of the career teacher. California: Kappa Delta Pi, 2000. p. 1-25.

WENDT, Janice; BAIN, Linda; JACKSON, Andrew. Fuller's concerns theory as tested on prospective Physical Education. Journal of Teaching in Physical Education, v. 1, n. 0, p. 66-70, Apr. 1981. 
ZIELINSKI, Edward; PRESTON, Denise. The evolution of preservice science teachers' concerns about teaching. In: ANNUAL MEETING OF THE NATIONAL ASSOCIATION OF RESEARCH IN SCIENCE TEACHING, 59., 1992, Boston. Annals... Boston: AERA, 1992. p. 1-20.

ZOUNHIA, Katerina; HATZIHARISTOS, Dimitris; EMMANOUEL, Kostas. Teaching Concerns of Greek Physical Education Student Teachers. Studies in Physical Culture and Tourism, v. 11, n. 2, p. 7388, 2004. 